\title{
HIRS channel 12 brightness temperature dataset and its correlations with major climate indices
}

\author{
L. Shi ${ }^{1}$, C. J. Schreck III ${ }^{2}$, and V. O. John ${ }^{3}$ \\ ${ }^{1}$ National Climatic Data Center, National Oceanic and Atmospheric Administration, Asheville, North Carolina, USA \\ ${ }^{2}$ Cooperative Institute for Climate and Satellites, North Carolina State University, Asheville, North Carolina, USA \\ ${ }^{3}$ Met Office Hadley Centre, Exeter, UK
}

Correspondence to: L. Shi (lei.shi@noaa.gov)

Received: 30 November 2012 - Published in Atmos. Chem. Phys. Discuss.: 21 December 2012

Revised: 7 June 2013 - Accepted: 11 June 2013 - Published: 23 July 2013

\begin{abstract}
A new version of the High-Resolution Infrared Radiation Sounder (HIRS) upper tropospheric water vapor channel (channel 12) brightness temperature dataset is developed using intersatellite calibrated data. In this dataset, only those pixels affected by upper tropospheric clouds are discarded. Compared to the previous version that was based on column-clear-sky data, the new version has much better daily spatial coverage. The HIRS observation patterns are compared to microwave sounder measurements. The differences between the two types of sounders vary with respect to brightness temperature with larger differences for higher (dry) values. Correlations between the HIRS upper tropospheric water vapor channel brightness temperatures and several major climate indices show strong signals during cold seasons. The selected climate indices track climate variation signals covering regions from the tropics to the poles. Qualitatively, moist signals are correlated with troughs and ascending branches of the circulation, while dry signals occur with ridges and descent. These correlations show the potential of using the upper tropospheric water vapor channel brightness temperature dataset together with a suite of many atmospheric variables to monitor regional climate changes and locate global teleconnection patterns.
\end{abstract}

\section{Introduction}

With data starting in 1978, the High-Resolution Infrared Radiation Sounder (HIRS) has the longest record among satellite sounding measurements. The satellites carrying HIRS include the Television Infrared Observation Satellite (TIROS-
$\mathrm{N})$, the operational National Oceanic and Atmospheric Administration (NOAA) polar orbiting satellite series (hereafter abbreviated as NOAA-\#, where \# is the satellite number), and the Meteorological Operational Satellite Program (METOP) operated by the European Organisation for the Exploitation of Meteorological Satellites (EUMETSAT). There are 20 channels in a HIRS instrument, among which channel 12 is designed to measure the upper tropospheric water vapor. Using data from early satellites, Wu et al. (1993) constructed an early analysis of HIRS channel 12 brightness temperature $\left(T_{\mathrm{B}}\right)$ climatology. Bates et al. (1996) studied intersatellite biases of channel $12 T_{\mathrm{B}}$ and developed an empirical method to intercalibrate $13 \mathrm{yr}$ of HIRS/2 data. Recently, Shi and Bates (2011) intercalibrated HIRS channel $12 T_{\mathrm{B}}$ data based on zonal averages of overlapping satellites and extended the time series to HIRS $/ 3$ and HIRS $/ 4$.

HIRS is one of several satellite sensors with a channel making routine measurements of upper tropospheric water vapor. Other satellite sensors include, from polar orbiting satellites, the Advanced Microwave Humidity Unit-B (AMSU-B) and the Microwave Humidity Sounder (MHS) (Buehler et al., 2008; John et al., 2012), and from geostationary satellites, the Geostationary Operational Environmental Satellites (GEOS) imager (Soden and Bretherton, 1993; Knapp, 2012), Meteosat Visible and InfraRed Imager (MVIRI) and Spinning Enhanced Visible and InfraRed Imager (SEVIRI) (Vandeberg et al., 1991; Picon et al., 2003; Brogniez et al., 2006, 2009). These sensors from different space agencies provide daily data with near-global coverage. The observations are valuable for climate model evaluations (Roca et al., 1997; Iacono et al., 2003; Brogniez et al., 2005; 
Chung et al., 2011) and climate index analyses (Jedlovec et al., 2000).

The value of climate indices for forecasting has been known for decades (Namias, 1950; Wallace and Gutzler, 1981; Barnston and Livezey, 1987; Thompson and Wallace, 2000; van den Dool et al., 2000). Perhaps the most valuable of these is the El Niño-Southern Oscillation (ENSO) (Ropelewski and Halpert, 1996), in which persistent sea surface temperature anomalies drive distinctive weather patterns around the globe. Other important teleconnection patterns include the Pacific Decadal Oscillation (PDO), the PacificNorth American (PNA) (Barnston and Livezey, 1987; Johnson and Feldstein, 2010) pattern, the North Atlantic Oscillation (NAO) (Barnston and Livezey, 1987; van den Dool et al., 2000), the Arctic Oscillation (AO) (Higgins et al., 2002), and the Antarctic oscillation (AAO) (Mo, 2000). Because these patterns evolve on timescales of weeks or more, they provide critical sources of long-range predictability.

HIRS measurements have been used to examine the modulation of upper tropospheric humidity associated with various climate indices and other large-scale circulations. Studies showed that HIRS upper tropospheric humidity closely tracks ENSO evolutions (Bates et al., 1996; McCarthy and Toumi, 2004, and Shi and Bates, 2011). HIRS channel 12 observations provided valuable information for examining the strong interaction between tropical and midlatitude planetary waves (Bates and Jackson, 2001) and changes in tropical circulations in the past three decades (Sohn and Park, 2010). A long-term HIRS channel 12 dataset was used in the evaluation of climate model simulations (Iacono et al., 2003). The trend and variability of upper tropospheric humidity were analyzed in various studies (Geer et al., 1999; Bates and Jackson, 2001; Bates et al., 2001; McCarthy and Toumi, 2004; Soden et al., 2005). The large-scale studies identified above were based on column-cloud-cleared data. But as the distribution of cloud frequencies ranges from $\sim 0.20$ to $\sim 0.95$ (Wylie et al., 2007), column-cloud-cleared data may not be representative of many weather systems. Using measurements from microwave sounders, John et al. (2011) illustrated possible limitations of clear-sky data. To expand the applications of the data, we develop a new above-cloud HIRS channel $12 T_{\mathrm{B}}$ dataset with improved sky coverage. This new dataset will be compared with previous versions and its relationship with various climate indices will be explored.

\section{HIRS channel 12 data}

For over three decades, HIRS measurements have been made from more than a dozen satellites. Due to differences in the channel's spectral response functions and independence in each instrument's calibration, biases exist from satellite to satellite (Shi et al., 2008). The most significant change in upper tropospheric water vapor measurement occurred when the central spectral response functions for channel 12 were shifted from 6.7 to $6.5 \mu \mathrm{m}$ as the HIRS instrument designs changed from HIRS/2 (on satellites TIROS-N and NOAA-6 to NOAA-14) to HIRS/3 (on satellites NOAA-15 to NOAA17). In addition to spectral response function changes, HIRS instruments from different polar orbiting satellites observe a location at different times of a day, which can introduce diurnal biases. As shown in Lindfors et al. (2011) and MacKenzie et al. (2012), the diurnal amplitudes for $T_{\mathrm{B}} \mathrm{s}$ from channel 12 are generally within $0.5 \mathrm{~K}$. Based on overlapping satellites' monthly zonal averages from the Equator to the poles, Shi and Bates (2011) quantified these combined intersatellite biases for HIRS channel 12 on TIROS-N, NOAA satellite series, and METOP-A. The combined intersatellite biases, except those between NOAA-14 and NOAA-15, were found to be within $\pm 1.8 \mathrm{~K}$. The biases between NOAA-14 and NOAA-15 can exceed $8 \mathrm{~K}$ due to the spectral response function shift. An intersatellite-calibrated global HIRS channel 12 dataset since 1978 using column-clear-sky data was developed. Using data from the tropics Shi and Bates (2011) showed that monthly differences of intercalibrated time series between satellites were mostly within $\pm 0.2 \mathrm{~K}$. The same intersatellite bias corrections are applied in the present study to adjust HIRS measurements to the same base satellite (NOAA-12) as that in the previous column-clear-sky version to form a climatologically homogenized time series.

\subsection{Removal of upper tropospheric clouds}

HIRS upper tropospheric water vapor processing can be affected by clouds in the upper troposphere. A method using $T_{\mathrm{B}}$ differences between the upper tropospheric water vapor channel and the window channel has long been used to identify upper tropospheric clouds (Soden, 2000). Clouds that reach the upper troposphere are usually associated with deep convective systems characterized by low infrared $T_{\mathrm{B}} \mathrm{s}$, therefore cold $T_{\mathrm{B}} \mathrm{s}$ in the window channel (near $11 \mu \mathrm{m}$ ) have also been used in identifying clouds. Past studies showed that upper tropospheric cloud-top temperatures range from less than $210 \mathrm{~K}$ for very cold organized clouds (Mapes and Houze, 1993; Zuidema, 2003) to 235-245 K for moderately cold clouds (Machado et al., 1998; Rossow and Pearl, 2007).

To evaluate the sensitivity of threshold values on cloud identification, we use the Radiative Transfer for TIROS Operational Vertical Sounder (RTTOV) (Saunders et al., 1999) to simulate the $T_{\mathrm{B}} \mathrm{s}$ of channels 12 and 8 in the presence of clouds. The simulation employs a sample of profiles collected by Chevallier (2001). The profiles were selected from European Centre for Medium-Range Weather Forecasts (ECMWF) reanalysis fields, with diverse atmospheric conditions including about 6000 cloudy profiles. The simulation results displaying the cloud-top pressure as a function of channel $8 T_{\mathrm{B}}$ and the difference between channels 8 and 12 are plotted in Fig. 1. Clouds with tops above $400 \mathrm{hPa}$ have distinctly low difference values between channels 8 and 12 . 


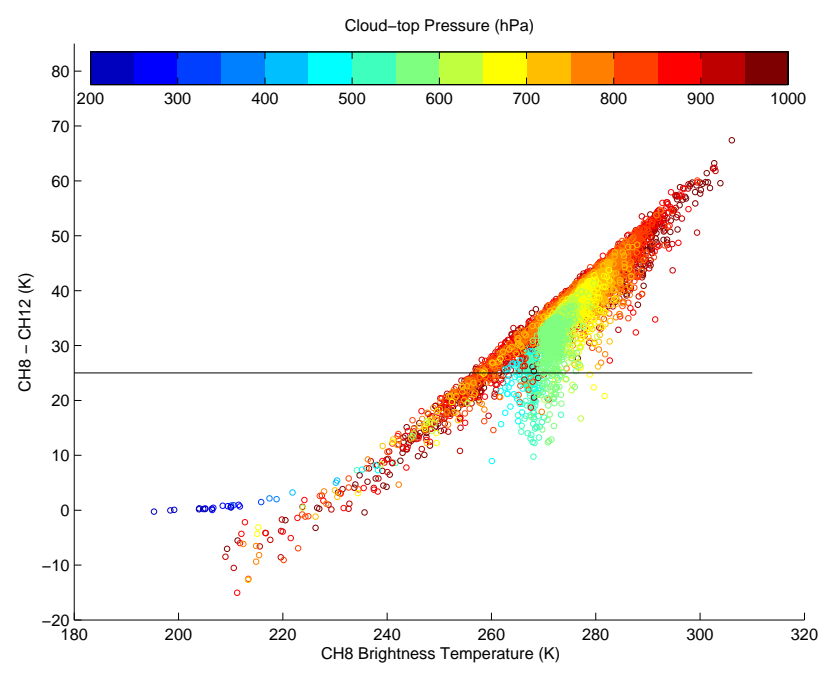

Fig. 1. RTTOV simulations of HIRS brightness temperature differences between channels 8 and 12 and channel 8 brightness temperatures based on global cloudy profiles. The primary threshold value for identification of upper tropospheric clouds is drawn.

Following the upper tropospheric cloud screening method developed by Soden (2000) and the RTTOV evaluation, we apply the following primary criterion to identify clouds in the upper troposphere:

$T_{\mathrm{ch} 8}-T_{\mathrm{ch} 12} \leq 25 \mathrm{~K}$.

In the above, $T_{\mathrm{ch} 8}$ and $T_{\mathrm{ch} 12}$ represent the $T_{\mathrm{B}} \mathrm{S}$ of the window channel 8 (at $11 \mu \mathrm{m}$ ) and water vapor channel 12 (at $6.7 \mu \mathrm{m})$, respectively. We tested the sensitivity of the threshold and found that by adding or reducing the " $T_{\operatorname{ch} 8}-T_{\mathrm{ch} 12}$ " threshold by $5 \mathrm{~K}$, the fraction of cloudy pixels increases or decreases by approximately $10 \%$ (absolute value). The window channel measurement $T_{\mathrm{ch} 8} \leq 235 \mathrm{~K}$ is also used as an additional quality control. The threshold values are adjusted over polar regions to account for the very low temperatures over land and ice surfaces during cold months, for which $T_{\mathrm{ch} 8}-T_{\mathrm{ch} 12} \leq 5 \mathrm{~K}$ and $T_{\mathrm{ch} 8} \leq 210 \pm 5 \mathrm{~K}(+5$ for the northern polar region and -5 for the southern polar region). The $T_{\mathrm{ch} 8}-T_{\mathrm{ch} 12}$ and $T_{\mathrm{ch} 8}$ threshold values change linearly with latitude between 40 and $60^{\circ} \mathrm{N}$, between the values in Eq. (1) and the polar threshold values. Figure 1 shows that the cloud removal method captures essentially all the profiles with cloud tops above $400 \mathrm{hPa}$. The method can also remove some low-to-middle level clouds that have small differences between channels 8 and 12 or have very low cloud-top temperatures. The cloud detection method in the present study identifies about $22-25 \%$ of pixels as clouds in the upper troposphere. In a cloud statistics study using HIRS, Wylie et al. (1994) showed that the global cloud frequency above $400 \mathrm{hPa}$ is $23.9 \%$. The frequency of upper tropospheric clouds identified in the present work is consistent with the cloud frequencies found in the study of Wylie et al. (1994) and in a subsequent study (Wylie et al., 2005). As a comparison, the cloud-removal process in the previous column-clear-sky version identified about $70 \%$ of pixels as cloudy pixels. It should be noted that the above cloud removing process aims at identifying clouds in the upper troposphere and it is designed to retain as much signal as possible for the teleconnection analyses to be discussed in subsequent sections, thus the algorithm retains clouds with tops below $400 \mathrm{hPa}$. As the $6.7 \mu \mathrm{m}$ channel weighting function spans a thick layer of the atmosphere, some clouds with tops below $400 \mathrm{hPa}$ may affect humidity retrievals. A discussion on the effect of clouds in the upper portion of the midtroposphere on humidity processing can be found in Brogniez et al. (2006), which is based on the upper tropospheric water vapor channel measurement from Meteosat.

\subsection{Comparison with the previous column-clear-sky version}

The previous version of the HIRS channel $12 T_{\mathrm{B}}$ data was based on column-clear-sky data (Shi and Bates, 2011). Pixels were removed when there was any cloud in the entire column of the atmosphere, even mid- and low-level clouds. As described in the previous section, the new version only removes pixels containing clouds in the upper troposphere. Figure 2 compares these two versions for a typical daily observation in a winter month. The data are mapped to $2.5^{\circ} \times 2.5^{\circ}$ grids The upper panel displays the new version of channel $12 T_{\mathrm{B}}$ data for 15 January 2011, and the lower panel shows the previous column-clear-sky version for the same day. The areas in black have no data, generally due to the cloud clearing.

Figure 2 shows that the new version (upper panel) has significantly fewer of these missing data points. In the previous version (lower panel), large areas of data were removed. In addition to convective systems, many of these data were associated with low-level stratiform clouds. While the new version generally has fewer missing data, a few mid- to highlatitude places actually get flagged with clouds more often in the new version than they did previously. These places tend to be the areas having very cold temperatures in winter months. For these scenarios the high-level-cloud removal procedure will need to be improved for future versions. Nonetheless, it already provides better spatial coverage than the previous version.

Figure 3 compares the $33 \mathrm{yr}$ (1979-2011) climatology of the new (top panel) and the previous (middle panel) version. The locations of maximum and minimum areas are consistent between the two maps. Both show low values of $T_{B} S$ (corresponding to higher humidity) over Indonesia, equatorial South America, and central Africa. High values of $T_{\mathrm{B}} \mathrm{s}$ (corresponding to dryer areas) are found over zonal belts along $20^{\circ} \mathrm{S}$ and $20^{\circ} \mathrm{N}$. However the $T_{\mathrm{B}}$ values in the new version are less than those in the previous version, and the $T_{\mathrm{B}}$ gradients are generally larger. 

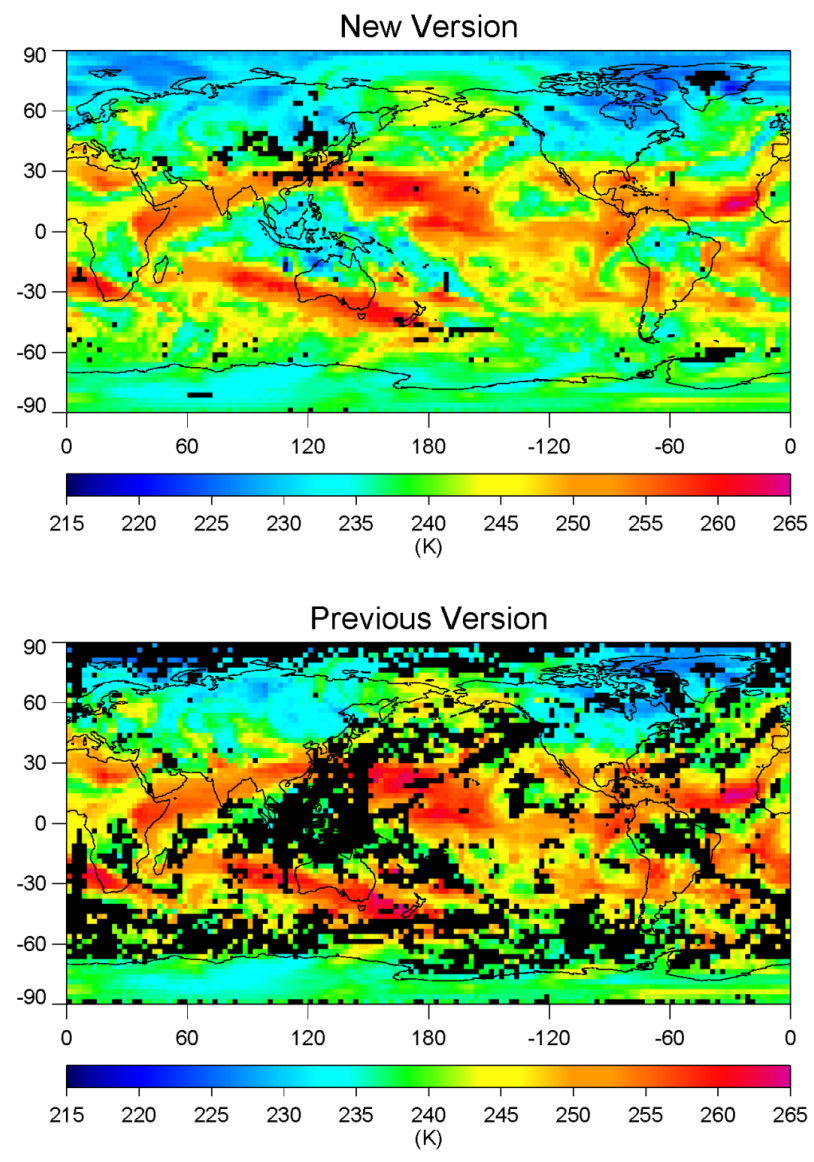

Fig. 2. Comparison of one-day's spatial coverage between the new version and the previous column-clear-sky version of Shi and Bates (2011). The example is taken from METOP-A observations on 15 January 2011.

The differences between the new and the previous versions are displayed in the bottom panel of Fig. 3. The largest differences (about $-5 \mathrm{~K}$ ) are located over the western equatorial Pacific Ocean and equatorial Indian Ocean where convective weather systems frequently occur. Differences of -3 to $-5 \mathrm{~K}$ also extend to other areas where Wylie et al. (2005) found total cloud frequencies of more than $80 \%$ in low and midlatitudes. Within each grid cell, the pixels over clouds are generally more humid and thus have lower $T_{\mathrm{B}}$ values than those of clear-sky pixels. By retaining the pixels over low and middle clouds, the averaged grid values become lower compared to the averaged values of column-clear-sky pixels.

There are several areas where differences between the new and the previous version are close to zero. Over the low and midlatitudes these small difference areas are located in the eastern South Pacific between the Equator and $30^{\circ} \mathrm{S}$, the South Atlantic between the Equator and $30^{\circ} \mathrm{S}$, and northern Africa and Saudi Arabia. These areas with small differences mostly correspond to places with lower cloud frequencies (Wylie et al., 2005). The minima off the coasts of South
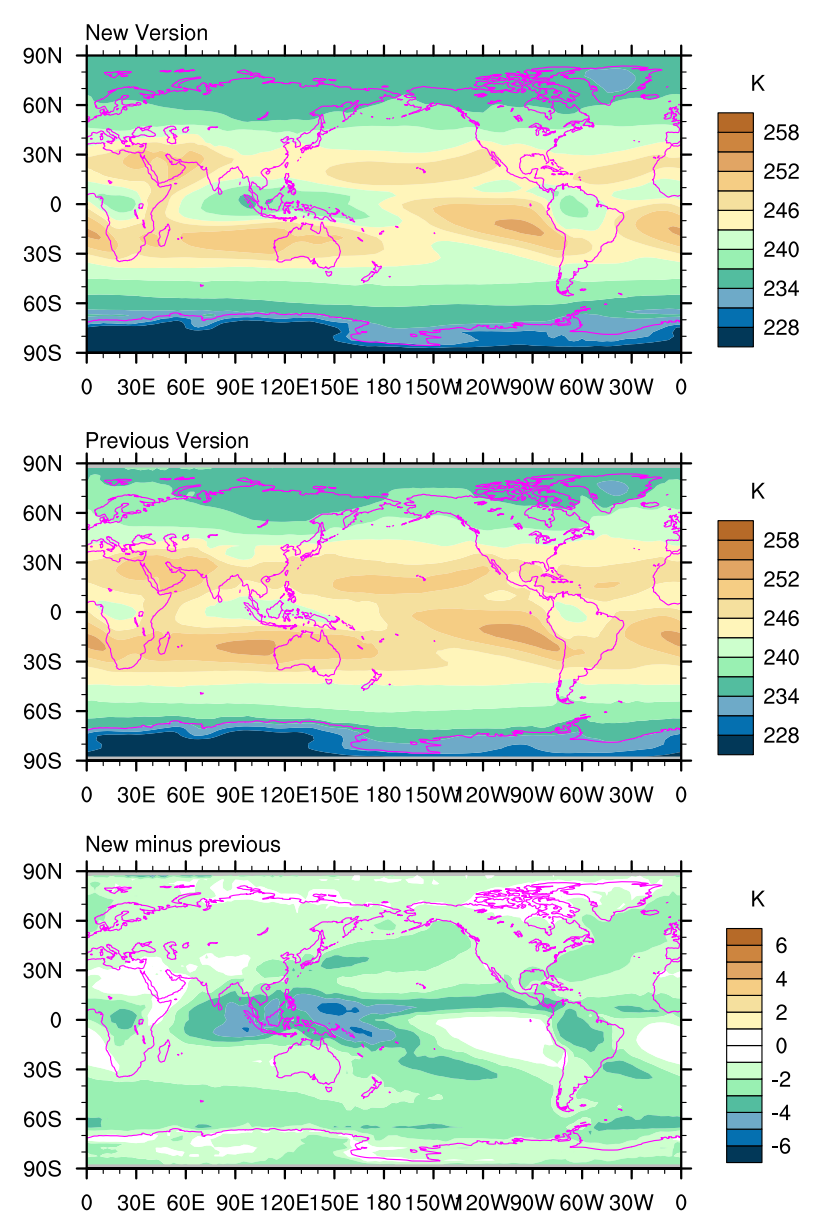

Fig. 3. The $33 \mathrm{yr}$ (1979-2011) HIRS channel $12 T_{\mathrm{B}}$ climatology maps for the new version (top panel) and the previous column-clearsky version of Shi and Bates (2011) (middle panel). The bottom panel shows the difference between the two versions.

America and the southern Africa shown in the bottom panel of Fig. 3 also correspond to the dry descending branches of the general circulations, shown as maxima in the top panel of Fig. 3. Small cloud frequency and generally dry conditions combine to produce these minima in the difference map.

Soden and Lanzante (1996) investigated the impact of the clear-sky sampling restriction on the HIRS moisture climatology. Their study compared clear-sky and all-sky radiosonde observations and suggested that the clear-sky sampling limitation can introduce a modest dry bias in the satellite derived clear-sky climatology. In a subsequent study, Lanzante and Gahrs (2000) showed that the effects of such bias are relatively small in the extratropics but may be 5$10 \%$ in the convectively active regions of the tropics. The bottom panel of Fig. 3 displays the heterogeneous nature of these differences. The difference from clear-sky sampling is larger over the equatorial western Pacific Ocean and the eastern Indian Ocean than it is over the eastern South Pacific and the South Atlantic. Using microwave sounder 
measurements to examine column-clear-sky sampling issues, John et al. (2011) illustrated bias values in terms of relative humidity for January and July 2008. Many of the areas with differences of -3 to $-5 \mathrm{~K}$ in Fig. 3 of the present study also exhibited column-clear-sky relative humidity biases of -5 to $-15 \%$ in Fig. 7 of John et al. (2011). It is noted that the previous clear-sky dry bias studies illustrated the differences between column-clear-sky data and all-sky or almost-all-sky data, while the patterns in Fig. 3 show the differences resulted from the inclusion of above-cloud data to column-clear-sky data. The difference observed in the present study will require more detailed investigation in the future.

\subsection{Monthly climatology}

Using $33 \mathrm{yr}$ of data from 1979 to 2011, we derived the climatological mean of each month (Fig. 4). The basic patterns in the tropics are similar to those in Wu et al. (1993), who displayed 1981-1988 channel 12 monthly climatology from $45^{\circ} \mathrm{N}$ to $45^{\circ} \mathrm{S}$. Figure 4 shows that in January, there is a long, dry belt in the northern tropics, strongest over the tropical Pacific. The driest regions are usually in the descending branch of the general circulation such as the Hadley cell. A channel $12 T_{\mathrm{B}}$ image is often better at locating the descending branch of the general circulation than are fields of cloud or outgoing longwave radiation because neither of those fields can tell if one cloud-free region is dryer than another, but the water vapor field can. In January, moist regions are found south of the Equator. The organized moist belt is usually associated with the Intertropical Convergence Zone (ITCZ). In July, the moist regions are north of the Equator, while the driest belt is in the southern tropics. The $T_{\mathrm{B}}$ gradient is smallest in April, indicating weak general circulations.

\section{Comparison of HIRS and microwave sounder measurements}

\subsection{Microwave sounder data}

The Advanced Microwave Sounder Unit-B (AMSU-B) instruments have been onboard NOAA satellites NOAA-15 to NOAA-17. A similar instrument, Microwave Humidity Sounder (MHS), has been on board the satellites in the Initial Joint Polar-Orbiting Operational Satellite System (IJPS) series. Among several channels on the microwave sounders, one channel is at $183.31 \pm 1.00 \mathrm{GHz}$ for making measurements of upper tropospheric water vapor. The microwave observations are affected by precipitating ice clouds, therefore ice cloud pixels are removed using a method developed by Buehler et al. (2007). Data from microwave sounders on NOAA-17 and METOP-A (one of the satellites in the IJPS series) are then combined to obtain daily gridded files of $T_{\mathrm{B}} \mathrm{S}$ on a $2.5^{\circ} \times 2.5^{\circ}$ resolution. A comparison between HIRS and microwave upper tropospheric water vapor channel measure- ments is done for January and July 2008 , similar to the analyses of John et al. (2011).

\subsection{Comparison results}

Figure 5 displays HIRS and microwave upper tropospheric channel $T_{\mathrm{B}} \mathrm{S}$ and their differences for January and July 2008. Bottom panels show the differences (microwave minus HIRS) as functions of microwave $T_{\mathrm{B}} \mathrm{s}$. Red symbols show mean differences and their standard deviations for $5 \mathrm{~K} T_{\mathrm{B}}$ bins. John et al. (2011) compared almost-all-sky and columnclear-sky AMSU-B upper tropospheric humidity, and found that there is considerable bias in the column-clear-sky dataset compared to almost-all-sky microwave measurements due to under-sampling of humid cases in the presence of clouds. They also showed that the clear-sky bias is significantly correlated with upper tropospheric humidity. In the present study we do a similar analysis to see how the new version of HIRS data compares with microwave measurements and whether the differences have a dependence on the measurement values.

Higher HIRS $T_{\mathrm{B}} \mathrm{s}$ are measured in the dry subsidence regions and lower $T_{\mathrm{B}} \mathrm{S}$ are measured over convectively active, humid ITCZ and monsoon regions (Fig. 5a-b). Microwave $T_{\mathrm{B}} \mathrm{s}$ displayed in panels $\mathrm{c}$ and $\mathrm{d}$ show similar patterns as those in panels $\mathrm{a}$ and $\mathrm{b}$, but are about $7-10 \mathrm{~K}$ higher compared to HIRS $T_{\mathrm{B}} \mathrm{s}$, owing to differences in water vapor emissivity at infrared and microwave frequencies. The microwave measurements are sensitive to a slightly lower layer in the upper troposphere compared to HIRS measurements, which also contributes to the differences.

The difference between the $T_{\mathrm{B}} \mathrm{s}$ should be larger for dry regions and smaller for humid regions because in a drier atmosphere the microwave channel requires a longer path length to get saturated compared to that in a humid atmosphere, so it samples a lower level of the atmosphere. Panels e and $f$ show the distribution of $T_{\mathrm{B}}$ differences and panels $\mathrm{g}$ and $\mathrm{h}$ show the $T_{\mathrm{B}}$ differences as a function of microwave $T_{\mathrm{B}} \mathrm{s}$. On average microwave $T_{\mathrm{B}} \mathrm{S}$ are $9 \mathrm{~K}$ higher than HIRS $T_{\mathrm{B}} \mathrm{S}$ for very dry cases $(>265 \mathrm{~K})$. As the $T_{\mathrm{B}} \mathrm{s}$ become lower, the differences decrease. At about $250 \mathrm{~K}$ the differences start to increase slightly with decreasing $T_{\mathrm{B}} \mathrm{s}$ for very wet cases. This differs from the column-clear-sky bias displayed in John et al. (2011).

To show what clear-sky differences would be between HIRS and microwave channels, we use the RTTOV and the Cloud Feedback Model Intercomparison Project Observation Simulator Package (COSP) (Bodas-Salcedo et al., 2011) to simulate differences for the same two months shown in Fig. 5, using cloud-removed profiles. The resulting differences are plotted in Fig. 6. The plots show that in dry cases the simulated clear-sky differences are close to those in Fig. 5g-h. Most of these cases have cloud-free conditions in the observation data. For very wet cases, the values in Fig. 6 decrease, but the corresponding ones in Fig. $5 \mathrm{~g}-\mathrm{h}$ increase 

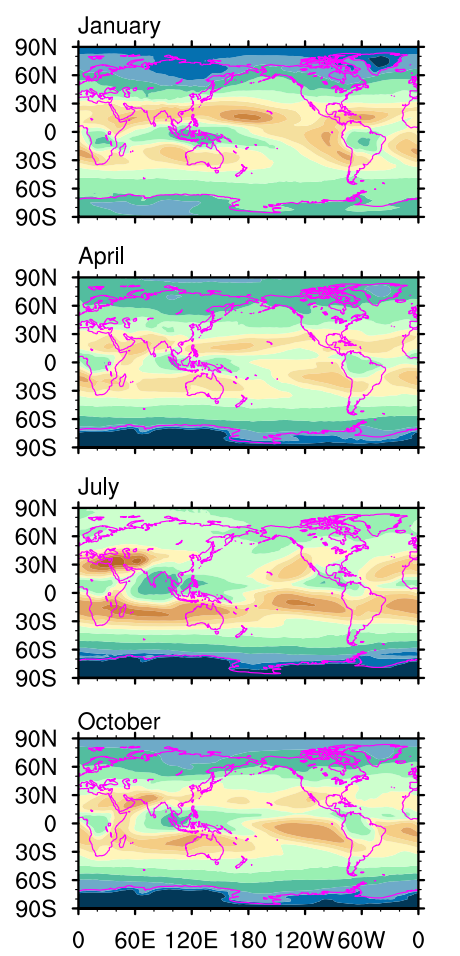

228231234237240243246249252255258
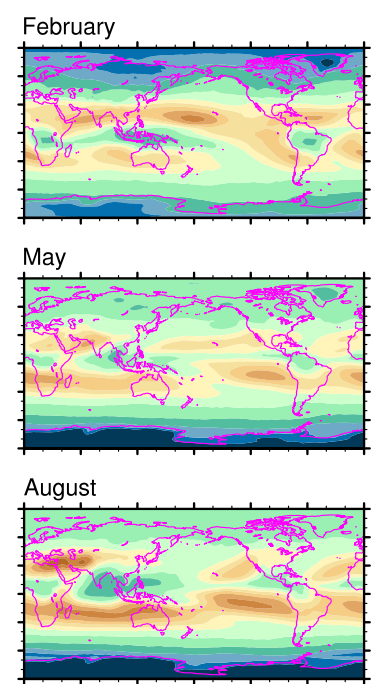

November

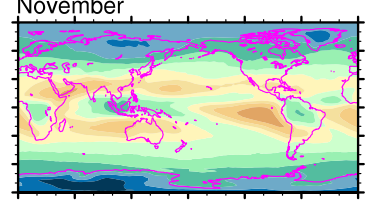

0 60E 120E 180 120W60W 0
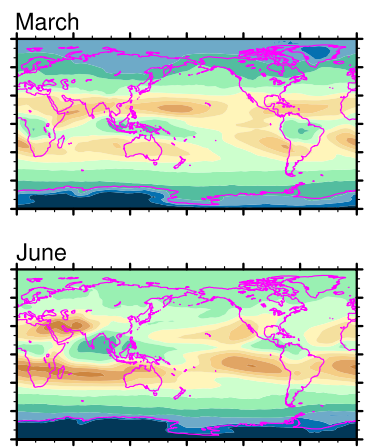

September

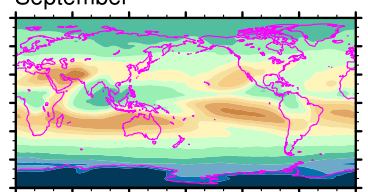

December

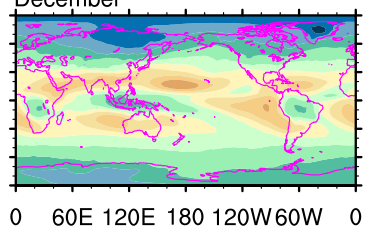

$\mathrm{K}$

Fig. 4. Monthly climatology of HIRS channel $12 T_{\mathrm{B}}$ based on data from 1979-2011.

slightly. The difference between the two figures may come from two different sources. For wet cases, convective lowto-middle clouds are often present, and the water vapor contents above these clouds are likely to be larger than those in cloud-free conditions. With possible increased water vapor above clouds, HIRS channel 12 detects lower $T_{\mathrm{B}}$ values compared to column-cloud-free simulations. This is consistent with column-cloud-free dry bias findings presented in Lanzante and Gahrs (2000) and John et al. (2011). Another effect may come from clouds with tops in the upper portion of the mid-troposphere. As shown in Fig. 1, some clouds with tops between 400 and $500 \mathrm{hPa}$ may not have been removed by the cloud screening criteria. These clouds in the upper portion of the mid-troposphere, though not at the level where the channel 12 weighting function peaks, may be sensed by the channel from the lower tail of the weighting function, and contribute to the reduction of HIRS $T_{\mathrm{B}}$ values. As the inclusion of these clouds can affect humidity retrievals, the screening of clouds from the upper portion of mid-troposphere will need to be performed before deriving humidity values. On the other hand, the effect from these clouds on applications involving $T_{\mathrm{B}}$ pattern analyses is generally small. One such example of applications is locating $T_{\mathrm{B}}$ teleconnection patterns using correlation analyses that will be discussed in the next section. The reduced $T_{\mathrm{B}}$ values are generally associated with humid and convective areas. Though they may overestimate humidity retrieval values, the effect they have on altering distribution patterns is qualitatively insignificant.

\section{A survey of channel $12 T_{B}$ correlations with climate indices}

The analysis of column-clear-sky channel $12 T_{\mathrm{B}}$ by Shi and Bates (2011) showed that distributions of the measurement are closely related to several climate indices, including the PDO index, the PNA index, and the East Central Tropical Pacific sea surface temperature (Niño 3.4) index. As an update, the one-point (pairwise) correlation maps between HIRS channel $12 T_{\mathrm{B}} \mathrm{s}$ and these climate indices are re-computed using the new version. In the present study we also extend the examination to several additional, widely used climate indices, including the NAO, AO, and AAO indices to provide a survey of the relationship of channel $12 T_{\mathrm{B}}$ with a wider range of major climate indices. The selected climate indices cover different geographic regions from the tropics to the poles, and their phases range from weeks to multidecades. The mean distribution of water vapor in the upper troposphere is a result of large-scale circulations. The correlations can show how closely the channel $12 T_{\mathrm{B}}$ distribution relates to the atmospheric variables used in tracking climate indices. The analysis also detects teleconnection patterns of 
a) HIRS $T_{B} S[K$ ] for January 2008
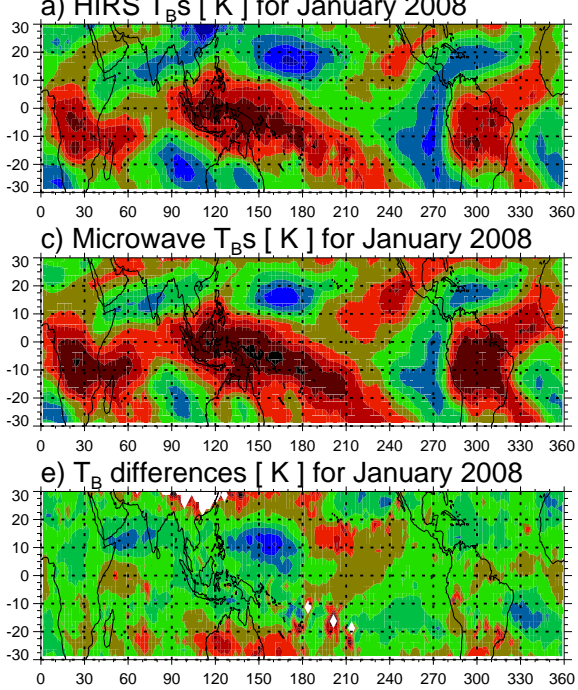

g) January 2008

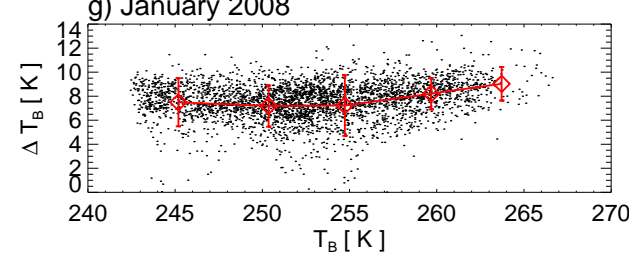

b) HIRS $T_{B} S[K$ ] for July 2008

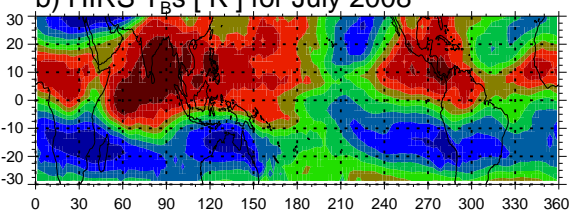

d) Microwave $T_{B} S$ [ K ] for July 2008
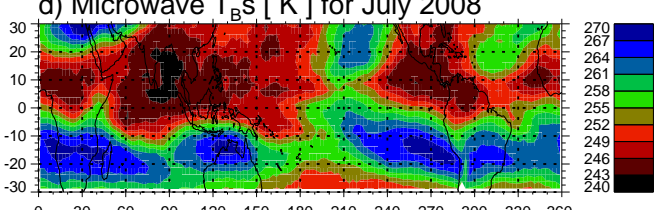

f) $T_{B}$ differences [ $K$ ] for July 2008

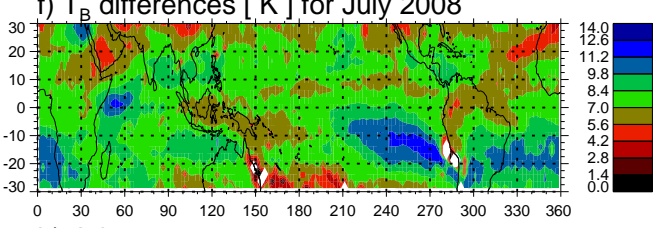

h) July 2008

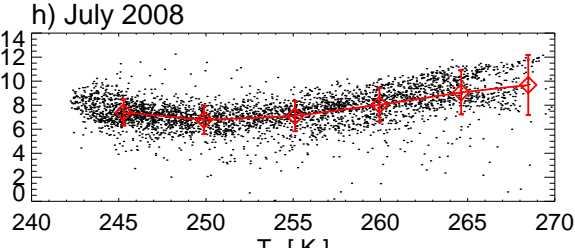

Fig. 5. HIRS and microwave channel $\mathrm{T}_{\mathrm{B}} \mathrm{s}$ and their differences for (left) January and for (right) July 2008 . Note that there is a $10 \mathrm{~K}$ difference in the color scale between the HIRS plots (panels $\mathrm{a}-\mathrm{b}$ ) and the microwave plots (panels $\mathrm{c}-\mathrm{d}$ ). Bottom panels show the differences (microwave minus HIRS) as function of microwave $T_{\mathrm{B}} \mathrm{s}$. Red symbols show mean differences and their standard deviations for $5 \mathrm{~K} T_{\mathrm{B}}$ bins.
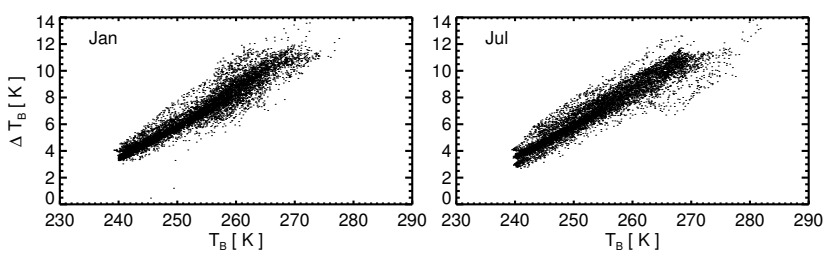

Fig. 6. RTTOV simulations of differences between microwave and HIRS $T_{\mathrm{B}} \mathrm{s}$ under clear-sky conditions for January and July 2008.

channel $12 T_{\mathrm{B}}$ with climate indices in various regions of the world.

The significance of the linear correlations at each point is evaluated with the $t$ statistics (Press et al., 2007, p. 746):

$t=r \sqrt{\frac{N-2}{1-r^{2}}}$,

where $r$ is the correlation and $N$ is the sample size, in this case $33 \mathrm{yr}$. Areas where the resulting two-tailed probability is greater than $10 \%$ are considered insignificant and will be stippled to deemphasize them.

\subsection{Correlation with Niño 3.4 index}

The Niño 3.4 index is based on the anomalies of sea surface temperature (SST) of the region $5^{\circ} \mathrm{N}-5^{\circ} \mathrm{S}$ and $120-170^{\circ} \mathrm{W}$.
It is often used to define ENSO events (Trenberth, 1997). To objectively locate areas that have large association with ENSO, we computed correlations between the time series of channel $12 \mathrm{~T}_{\mathrm{B}}$ at each grid point and the time series of Niño 3.4 SST anomaly (Fig. 7). As the ENSO events are more active during boreal winter season, the correlation map for December, January, and February (DJF) is shown. Because lower values of channel $12 T_{\mathrm{B}}$ generally represent higher water vapor contents, negative correlations (blue colors) in the figure reflect positive correlations between higher water vapor and the Niño 3.4 index.

The figure shows that the highest absolute correlation $(-0.8)$ between channel $12 T_{\mathrm{B}}$ and Niño 3.4 anomalies is over the central equatorial Pacific. Large correlations of the opposite sign are found over the western Pacific near Indonesia and in the subtropics, one at $20-30^{\circ} \mathrm{N}$ and another at $20-30^{\circ} \mathrm{S}$ over the Pacific. These areas with positive correlations correspond to descending branches of the atmospheric circulations during El Niño. The increase in Niño 3.4 SST likely facilitates the transportation of more moisture into the upper troposphere over the central and eastern equatorial Pacific, while the subsidence may dry the upper troposphere over both the northern and southern subtropical Pacific. The increase of SST in the eastern Pacific can affect regions outside of the tropics by altering prevailing wind patterns around the globe. For example, negative 


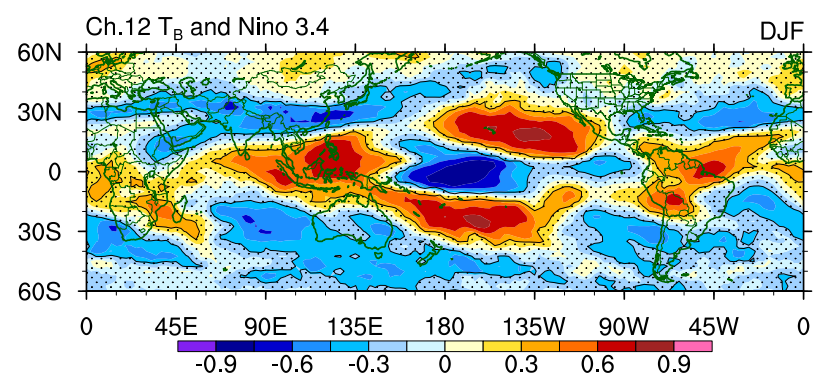

Fig. 7. Correlations between channel $12 T_{\mathrm{B}}$ and Niño 3.4 index for DJF. Grids that are considered insignificant using a $t$ test are stippled to deemphasize them and are separated by contour lines.

correlations (positive correlations between water vapor and Niño 3.4 SST) are found over the subtropical South Indian Ocean and eastern South Pacific Ocean. Similar correlation analysis was performed in Shi and Bates (2011) between the Niño 3.4 SST index and column-clear-sky HIRS upper tropospheric humidity. The high correlation areas (both positive and negative) in Fig. 7 correspond very well with those shown in Shi and Bates (2011).

\subsection{Correlation with PDO index}

The PDO index is tracked from observed Pacific Ocean SST and sea level pressure patterns (Mantua et al., 1997). The signature of PDO is most significant in the North Pacific and North America, with secondary signatures in the tropics (Mantua and Hare, 2002). Minobe (1999) found that 20th century PDO fluctuations were most energetic around bidecadal and half-century timescales. PDO phases are much longer than ENSO events, which typically last for 6 to 18 months. However, there is a strong linkage between PDO and ENSO events. For example, Newman et al. (2003) found that both interannual and decadal timescales of PDO can be well modeled as the sum of direct forcing by ENSO.

The correlations between channel $12 T_{\mathrm{B}} \mathrm{S}$ and the PDO index for DJF are shown in Fig. 8. Negative correlations with $T_{\mathrm{B}}$ reflect positive correlations between water vapor and the PDO index. The figure shows that relatively large negative correlations are found in midlatitudes of the Pacific Ocean and in the eastern-central equatorial Pacific. There is a positive correlation area in the eastern Pacific near $20^{\circ} \mathrm{N}$, where water vapor is likely reduced by the subsidence and thus positive correlations with $T_{\mathrm{B}}$ is enhanced. The similarity in the locations of negative and positive centers between Figs. 7 and 8 confirms the strong linkage between PDO and ENSO events. However, the negative belt in midlatitudes of the PDO correlation map is much stronger than that in Fig. 7, reflecting the possible increase of water vapor from longer phases of SST increases. Compared to the channel $12 T_{\mathrm{B}}$ and PDO analysis in Shi and Bates (2011), the large negative correlations in midlatitudes of the Pacific are more organized, a result of

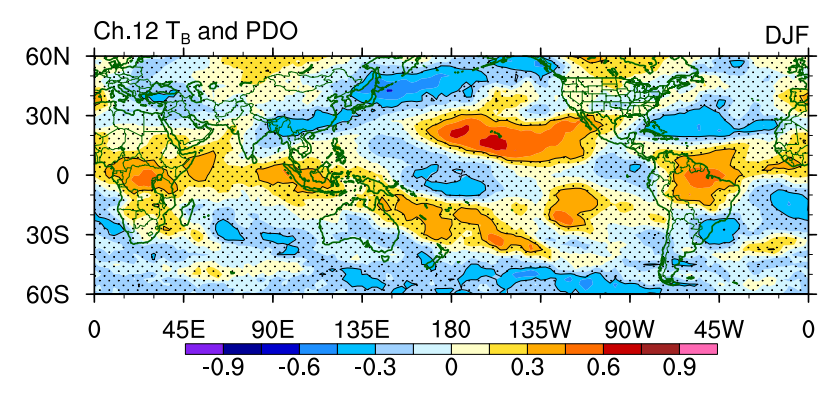

Fig. 8. Same as Fig. 7 for correlations between channel $12 T_{\mathrm{B}}$ and PDO index.

better water vapor representation in this area compared to the previous column-clear-sky version.

\subsection{Correlation with PNA index}

The PNA pattern is one of the low-frequency variabilities in the northern extratropics. Wallace and Gutzler (1981) first identified the correlated mid- to upper-tropospheric geopotential heights over the North Pacific and North America. The positive phase of the PNA is characterized by a region of above-average geopotential heights at 500 and $700 \mathrm{hPa}$ in northern Canada and the northwestern United States and an area around Hawaii. In the meantime below-average geopotential heights are centered in mid- to high latitudes over the North Pacific and in the southeastern United States. Calculation of the PNA index was described in detail by Barnston and Livezey (1987), and the sensitivity of the index and the pattern to analysis technique were also studied by van den Dool et al. (2000) and Chen and Van den Dool (2003). The PNA pattern is present on timescales from weeks to years (Blackmon et al., 1984). Studies found that the PNA index is closely related to regional climate in various parts of the world such as temperature and precipitation of the United States (Leathers et al., 1991), Indian summer monsoon rainfall (Peings et al., 2009), and sea ice over the western Arctic (L'Heureux et al., 2008).

Figure 9 displays the correlations of HIRS channel $12 T_{\mathrm{B}} \mathrm{S}$ with the PNA index for DJF. During the boreal winter there are high correlations of channel $12 T_{\mathrm{B}}$ with the PNA index. The PNA is associated with a wave train that has four waves centered over the subtropical Pacific, the Gulf of Alaska, northwestern North America, and southeastern North America. Evidence for this wave train can be seen in the alternating positive and negative correlations with channel $12 T_{\mathrm{B}}$. These patterns indicate a negative correlation between geopotential height and humidity. Such a relationship may be expected as subsidence within ridges would dry the column while ascent within troughs would moisten it.

Particularly notable is the broad area of positive correlations near Hawaii. The positive PNA is associated with an enhanced subtropical ridge in this region, and the 


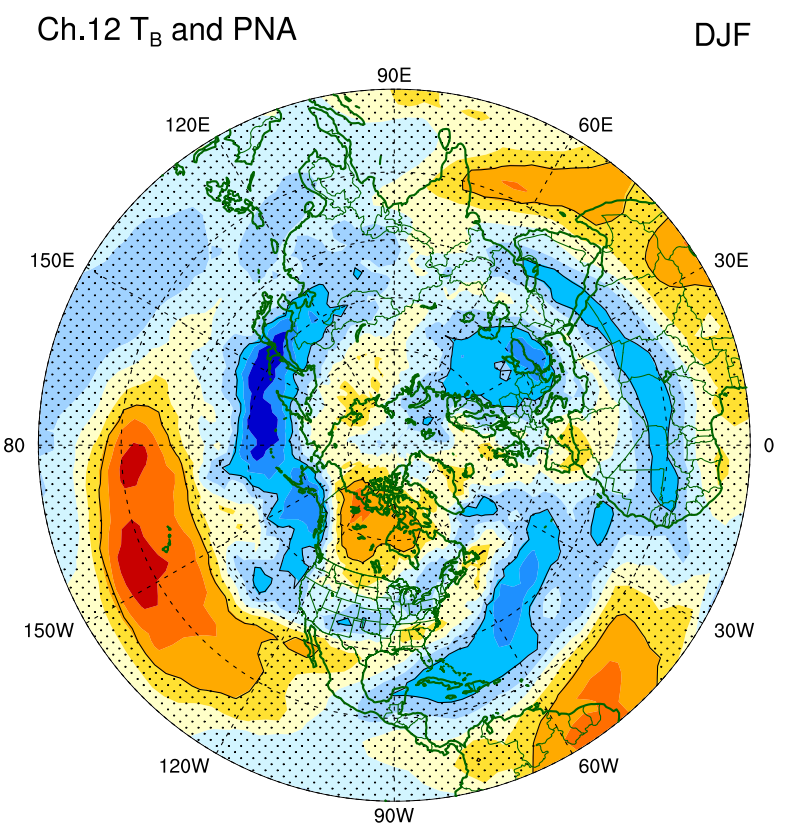

$\begin{array}{lllllllll}-0.9 & -0.6 & -0.3 & 0 & 0.3 & 0.6 & 0.9\end{array}$

Fig. 9. Same as Fig. 7 for correlations between channel $12 T_{\mathrm{B}}$ and PNA index.

positive correlations are consistent with the associated drying. Schreck et al. (2012) found a similar relationship between channel $12 T_{\mathrm{B}}$ and the subtropical ridge that was associated with the Madden-Julian Oscillation. Compared to a typical positive phase of PNA pattern in which there is a region of below-average geopotential heights over the southeastern United States, the channel $12 T_{\mathrm{B}}$ correlation map shows negative correlations in lower latitudes (around Cuba) and extends more significantly to the east. The southwarddisplaced negative correlations are possibly the result of higher water vapor content in the tropics. The locations of the high correlation centers (both positive and negative) are the same as those in the column-clear-sky channel $12 T_{\mathrm{B}}$ and PNA analysis DJF map of Shi and Bates (2011). However the negative correlative values in midlatitudes over the North Pacific are higher for the present case that includes above-cloud water vapor.

\subsection{Correlation with NAO index}

Another low-frequency pattern that reflects large-scale changes in the atmospheric wave and jet stream patterns over North America, Europe, and North Africa is tracked as the NAO index. The NAO pattern was also identified by Wallace and Gutzler (1981). The positive phase of NAO is characterized by above-average geopotential heights over the subtropical-midlatitude Atlantic Ocean and western Europe. There is an area of associated below-average geopotential heights around Greenland and Iceland. Many studies showed profound influences of NAO on various regional climates, such as the North Atlantic cloud cover and marine response to NAO (Previdi and Veron, 2007; Patara et al., 2011), teleconnection between NAO and climate downstream of the Tibetan Plateau ( $\mathrm{Li}$ et al., 2008), the influence of NAO on European precipitation (Vicente-Serrano and López-Moreno, 2008; Folland et al., 2009), the influence of NAO on air pollution transport (Christoudias et al., 2012), and the relationship of Great Lakes ice cover variability to NAO (Bai et al., 2012).

Figure 10 displays the correlation map between HIRS channel $12 T_{\mathrm{B}} \mathrm{S}$ and NAO for the boreal winter. The correlation pattern is in good agreement with the positive phase of NAO. High positive correlations are found over the Mediterranean and Europe, while large negative correlations occur over Greenland. As with the PNA, these patterns are consistent with a negative correlation between moisture and geopotential height. Another negative correlation area around $20^{\circ} \mathrm{N}$ of the eastern Atlantic is also prominent. During the positive phase when geopotential heights over the subtropical-midlatitude Atlantic Ocean and western Europe increase, the strengthened atmospheric circulation may create a more favorable condition for transportation of water vapor into the tropical upper troposphere.

\subsection{Correlations with $\mathrm{AA}$ and $\mathrm{AAO}$ indices}

With observations from polar-orbiting satellites, HIRS data have a complete areal coverage of the polar regions on a daily basis. This makes it possible to examine the correlations of HIRS channel $12 T_{\mathrm{B}} \mathrm{s}$ with two polar climate indices, the AO and AAO. In the middle and high latitudes especially in dry areas, HIRS channel 12 data are affected by temperatures in the middle and upper troposphere. In locations where water vapor content is small, a large portion of radiance measured by HIRS channel 12 comes from temperature. Though the temperature effect increases in higher latitudes, the measurement continues to be valuable in tracking changes in atmospheric circulation patterns. In measurements over high latitudes water vapor plays a less dominant role compared to in tropical cases. The observation in higher latitudes represents a combined signal from both water vapor and temperature.

The patterns of AO and AAO are defined as the first leading mode from the empirical orthogonal function analysis of monthly mean height anomalies at $1000 \mathrm{hPa}$ in the Northern Hemisphere for $\mathrm{AO}$ and at $700 \mathrm{hPa}$ in the Southern Hemisphere for AAO. In the positive phase of AO, there is a positive anomaly region over the eastern North Atlantic and western Europe between 40 and $50^{\circ} \mathrm{N}$, and another positive region over the central North Pacific at $50^{\circ} \mathrm{N}$. Negative anomalies are found around the North Pole. In the positive phase of $\mathrm{AAO}$, there is a belt of positive anomalies in the southern 
Ch.12 $\mathrm{T}_{\mathrm{B}}$ and $\mathrm{NAO}$

DJF
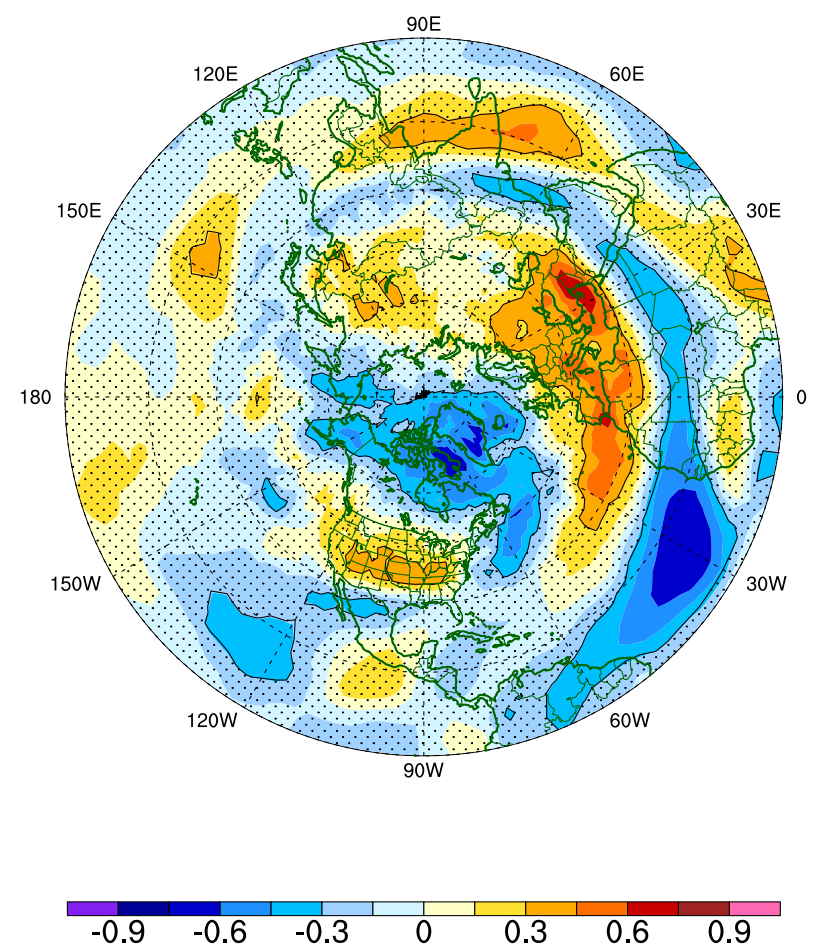

Fig. 10. Same as Fig. 7 for correlations between channel $12 T_{\mathrm{B}}$ and NAO index.

Indian Ocean between 40 and $50^{\circ} \mathrm{S}$ and there is another positive anomaly region in the southern Pacific near southern New Zealand. Negative anomalies are centered over Antarctica.

The AO and AAO have profound influences on environmental variables in high latitude regions. For example, Yu et al. (2012) used both surface observational data and global models to show that among several climate indices including the $\mathrm{AAO}$, the Pacific-South American teleconnection and ENSO, the most important contribution to the trends of Antarctic sea level pressure and surface temperature comes from AAO. Numerous studies showed that $\mathrm{AO}$ and $\mathrm{AAO}$ also have far-reaching influences beyond polar regions. Lim and Schubert (2011) revealed that both winter mean temperature anomalies and the number of days of extreme cold in the southeastern United States are closely linked to variations in AO especially in the recent past (1981-2008). Choi et al. (2012) showed that the frequency of summer tropical cyclones in Japan, Korea, and Taiwan in the middle latitudes of East Asia, has a positive correlation with $\mathrm{AO}$ occurring during the preceding spring, while summer tropical cyclone frequency in the Philippines, located in the low latitudes, has a negative correlation with the $\mathrm{AO}$ of the preceding spring. Park et al. (2011) studied changes in the characteristics of cold surges over East Asia associated with the $\mathrm{AO}$ and found that the blocking type of cold surge tends to occur during
Ch.12 $\mathrm{T}_{\mathrm{B}}$ and $\mathrm{AO} \quad$ DJF
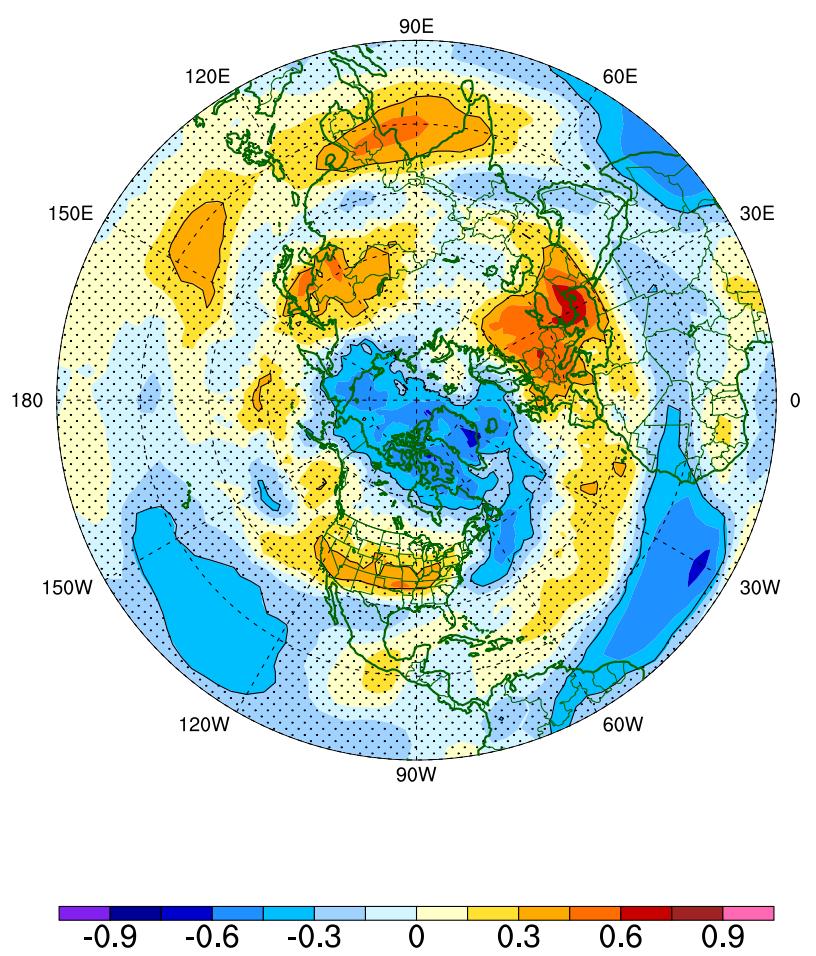

Fig. 11. Same as Fig. 7 for correlations between channel $12 T_{\mathrm{B}}$ and $\mathrm{AO}$ index.

negative AO periods. Since the AO and AAO have the largest variability during the cold seasons, the loading patterns primarily capture characteristics of the cold season patterns. However, Rigor et al. (2002) found that the memory of the wintertime $\mathrm{AO}$ has its signals through most of the subsequent year. Spring and autumn surface air temperature and summertime sea ice concentration are all strongly correlated with the $\mathrm{AO}$ index for the previous winter. It was hypothesized that these delayed responses reflect the dynamical influence of the $\mathrm{AO}$ on the thickness of the wintertime sea ice, whose persistent "footprint" is reflected in the heat fluxes during the subsequent spring, in the extent of open water during the subsequent summer, and the heat liberated in the freezing of the open water during the subsequent autumn.

Figures 11 and 12 display the correlations of HIRS channel $12 T_{\mathrm{B}}$ with AO and AAO for their perspective cold seasons, respectively. Figure 11 shows that the highest positive correlation with the AO is located over Europe. Compared to the positive $\mathrm{AO} 1000 \mathrm{hPa}$ geopotential pattern, the most significant positive correlation region over the eastern North Atlantic and Europe is slightly further east. Unlike the positive phase of AO where there is a single positive geopotential anomaly area over the central North Pacific in the AO empirical orthogonal function pattern of $1000 \mathrm{hPa}$ height anomalies, in the HIRS channel $12 T_{\mathrm{B}}$ correlation maps there are 
Ch.12 $\mathrm{T}_{\mathrm{B}}$ and $\mathrm{AAO}$

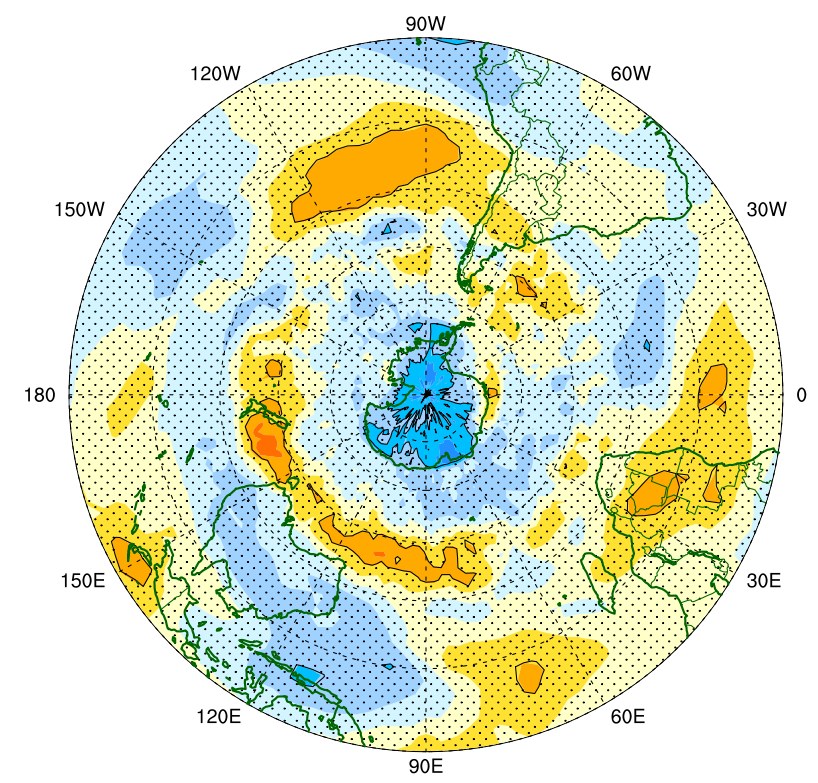

Fig. 12. Same as Fig. 7 for correlations between channel $12 T_{\mathrm{B}}$ and AAO index for JJA.

two positive correlation centers, one over northeast Asia and another over the northwestern United States. The differences compared to the $1000 \mathrm{hPa}$ height anomaly $\mathrm{AO}$ pattern may be due to drier air over land surfaces reflected by higher $T_{\mathrm{B}} \mathrm{S}$ compared to ocean surfaces. A comparison between Fig. 11 and Fig. 10 shows large similarities between the correlation maps of $\mathrm{AO}$ and NAO indices as both indices track northern high latitude patterns. However, the NAO correlation map exhibits much more significant signals over the Atlantic, where both correlation values and high significance areas are notably larger than those in the AO correlation map.

In Fig. 12, the map for southern high latitudes for the months of June, July, and August (JJA) closely resembles the positive phase of AAO. In addition to the positive anomaly centers of the AAO positive phase, there are large positive correlations over the southeastern Pacific, southern Africa, the midlatitude South Atlantic, and near the Equator at $150^{\circ} \mathrm{E}$. These high positive correlation features show strong hemisphere-wide teleconnections of AAO.

\section{Summary}

A new version of the HIRS channel $12 T_{\mathrm{B}}$ dataset is developed using intersatellite calibrated data. A cloud screening is designed to only remove pixels containing clouds in the upper troposphere. Pixels with clouds in the mid- and lower troposphere remain in the dataset. Compared to the previous version of column-clear-sky dataset, the new version retains more pixels with high water vapor content and provides a much better spatial coverage on a daily basis. The new version also reduces the dry bias inherent in previous columncloud-cleared datasets.

The observations from HIRS and from microwave sounder measurements show very similar patterns, though HIRS measurements are about $7-10 \mathrm{~K}$ colder than those from microwave sounders. The differences are larger for dry regions over which the microwave channel requires a longer path length to become saturated so it samples a lower atmospheric level. The differences for wet cases are slightly larger due to two different effects. One possible effect may come from the reduction of HIRS $T_{\mathrm{B}}$ values from pixels above convective low-to-middle clouds. Another effect may come from clouds with tops in the upper portion of the mid-troposphere. Though these clouds are not at the level where HIRS weighting function peaks, they can contribute to the radiance through the lower tail of the HIRS channel 12 weighting function. Future work to include screening of these clouds and to quantitatively assess their effect will be beneficial.

Correlations of channel $12 T_{\mathrm{B}}$ with several major climate indices ranging from the tropics to the poles are examined. The correlation patterns with Niño 3.4, PDO, and PNA indices are very similar to the results derived from the previous version of column-clear-sky data shown in Shi and Bates (2011), confirming that either the new version or columnclear-sky version is able to capture major sources of climate variability. It is noteworthy, however, that the new version provides clearer signals in the convective regions since more data are retained there. In the present study, correlations of channel $12 T_{\mathrm{B}}$ with $\mathrm{NAO}, \mathrm{AO}$, and AAO indices are also calculated. The correlation patterns in the cold seasons indicate an inverse relationship between moisture and geopotential height, with enhanced moisture in the troughs and drying in the ridges. The correlation analysis shows the potential of using channel $12 T_{\mathrm{B}}$ to monitor long-term changes in large-scale atmospheric circulation and for locating teleconnections of regional systems with major global climate systems.

As the new version of channel $12 T_{\mathrm{B}}$ dataset provides much better daily spatial coverage, it can be used to track the movement of weather systems globally on daily basis. For example, the use of HIRS channel $12 T_{\mathrm{B}}$ to track tropical waves is explored in Schreck et al. (2012). With daily global observation, the channel $12 T_{\mathrm{B}}$ dataset adds to the suite of observational measurements for monitoring weather and climate systems. 
Acknowledgements. The authors thank Darren Jackson of Cooperative Institute for Research in Environmental Sciences, University of Colorado at Boulder for providing all-sky HIRS/2 data. The Niño 3.4, PDO, PDA, NAO, AA, and AAO indices are obtained from NOAA Climate Prediction Center. Carl Schreck received support for this study from NOAA NCDC's Climate Data Record Program. Viju John was supported by the Joint DECC/Defra Met Office Hadley Centre Climate Programme (GA01101), the UK JWCRP, and EUMETSAT CMSAF. We thank David Parker of UK Met Office for valuable comments and thank two anonymous reviewers for constructive comments and helpful suggestions.

Edited by: G. Vaughan

\section{References}

Bai, X., Wang, J., Sellinger, C., Clites, A., and Assel, R.: Interannual variability of Great Lakes ice cover and its relationship to NAO and ENSO, J. Geophys. Res., 117, C03002, doi:10.1029/2010jc006932, 2012.

Barnston, A. G. and Livezey, R. E.: Classification, Seasonality and Persistence of Low-Frequency Atmospheric Circulation Patterns, Mon. Weather Rev., 115, 1083-1126, doi:10.1175/15200493(1987)115<1083:csapol>2.0.co;2, 1987.

Bates, J. J. and Jackson, D. L.: Trends in upper-tropospheric humidity, Geophys. Res. Lett., 28, 1695-1698, 2001.

Bates, J. J., Wu, X., and Jackson, D. L.: Interannual variability of upper-troposphere water vapor band brightness temperature, J. Climate, 9, 427-438, 1996.

Bates, J. J., Jackson, D. L., Breon, F. M., and Bergen, Z. D.: Variability of tropical upper tropospheric humidity 1979-1998, J. Geophys. Res.-Atmos., 106, 32271-32281, 2001.

Blackmon, M. L., Lee, Y. H., and Wallace, J. M.: Horizontal Structure of $500 \mathrm{mb}$ Height Fluctuations with Long, Intermediate and Short Time Scales, J. Atmos. Sci., 41, 961980, doi:10.1175/1520-0469(1984)041<0961:hsomhf >2.0.co;2, 1984.

Bodas-Salcedo, A., Webb, M. J., Bony, S., Chepfer, H., Dufresne, J. L., Klein, S. A., Zhang, Y., Marchand, R., Haynes, J. M., Pincus, R., and John, V. O.: COSP: Satellite simulation software for model assessment, B. Am. Meteorol. Soc., 92, 1023-1043, doi:10.1175/2011bams2856.1, 2011.

Brogniez, H., Roca, R., and Picon, L.: Evaluation of the distribution of subtropical free tropospheric humidity in AMIP-2 simulations using METEOSAT water vapor channel data, Geophys. Res. Lett., 32, L19708, doi:10.1029/2005g1024341, 2005.

Brogniez, H., Roca, R., and Picon, L.: A clear-sky radiance archive from Meteosat "water vapor" observations, J. Geophys. Res.Atmos., 111, D21109, doi:10.1029/2006jd007238, 2006.

Brogniez, H., Roca, R., and Picon, L.: Study of the Free Tropospheric Humidity Interannual Variability Using Meteosat Data and an Advection-Condensation Transport Model, J. Climate, 22, 6773-6787, doi:10.1175/2009jcli2963.1, 2009.

Buehler, S. A., Kuvatov, M., Sreerekha, T. R., John, V. O., Rydberg, B., Eriksson, P., and Notholt, J.: A cloud filtering method for microwave upper tropospheric humidity measurements, Atmos. Chem. Phys., 7, 5531-5542, doi:10.5194/acp-7-5531-2007, 2007.
Buehler, S. A., Kuvatov, M., John, V. O., Milz, M., Soden, B. J., Jackson, D. L., and Notholt, J.: An upper tropospheric humidity data set from operational satellite microwave data, J. Geophys. Res.-Atmos., 113, D14110, doi:10.1029/2007jd009314, 2008.

Chen, W. Y. and Van den Dool, H.: Sensitivity of Teleconnection Patterns to the Sign of Their Primary Action Center, Mon. Weather Rev., 131, 2885-2899, doi:10.1175/15200493(2003)131<2885: sotptt>2.0.co;2, 2003.

Chevallier, F.: Sampled databases of 60-level atmospheric profiles from the ECMWF analyses. EUMETSAT/ECMWF SAF Programme Research Rep. 4, 27 pp., 2001.

Choi, K. S., Wu, C. C., and Byun, H. R.: Possible connection between summer tropical cyclone frequency and spring Arctic Oscillation over East Asia, Clim. Dynam., 38, 2613-2629, doi:10.1007/s00382-011-1088-z, 2012.

Christoudias, T., Pozzer, A., and Lelieveld, J.: Influence of the North Atlantic Oscillation on air pollution transport, Atmos. Chem. Phys., 12, 869-877, doi:10.5194/acp-12-869-2012, 2012.

Chung, E. S., Soden, B. J., Sohn, B. J., and Schmetz, J.: Modelsimulated humidity bias in the upper troposphere and its relation to the large-scale circulation, J. Geophys. Res.-Atmos., 116, doi:10.1029/2011jd015609, D10110, 2011.

Folland, C. K., Knight, J., Linderholm, H. W., Fereday, D., Ineson, S., and Hurrell, J. W.: The Summer North Atlantic Oscillation: Past, Present, and Future, J. Climate, 22, 1082-1103, doi:10.1175/2008jcli2459.1, 2009.

Geer, A. J., Harries, J. E., and Brindley, H. E.: Spatial patterns of climate variability in upper-tropospheric water vapor radiances from satellite data and climate model simulations, J. Climate, 12, 1940-1955, 1999.

Higgins, R. W., Leetmaa, A., and Kousky, V. E.: Relationships between climate variability and winter temperature extremes in the United States, J. Climate, 15, 1555-1572, doi:10.1175/15200442(2002)015<1555:Rbcvaw>2.0.Co;2, 2002.

Iacono, M. J., Delamere, J. S., Mlawer, E. J., and Clough, S. A.: Evaluation of upper tropospheric water vapor in the NCAR Community Climate Model (CCM3) using modeled and observed HIRS radiances, J. Geophys. Res.-Atmos., 108, 4037, doi:10.1029/2002jd002539, 2003.

Jedlovec, G. J., Lerner, J. A., and Atkinson, R. J.: A satellitederived upper-tropospheric water vapor transport index for climate studies, J. Appl. Meteorol., 39, 15-41, doi:10.1175/15200450(2000)039<0015:asdutw>2.0.co;2, 2000.

John, V. O., Holl, G., Allan, R. P., Buehler, S. A., Parker, D. E., and Soden, B. J.: Clear-sky biases in satellite infrared estimates of upper tropospheric humidity and its trends, J. Geophys. Res.Atmos., 116, D14108, doi:10.1029/2010jd015355, 2011.

John, V. O., Holl, G., Buehler, S. A., Candy, B., Saunders, R. W., and Parker, D. E.: Understanding intersatellite biases of microwave humidity sounders using global simultaneous nadir overpasses, J. Geophys. Res.-Atmos., 117, D02305, doi:10.1029/2011jd016349, 2012.

Johnson, N. C. and Feldstein, S. B.: The Continuum of North Pacific Sea Level Pressure Patterns: Intraseasonal, Interannual, and Interdecadal Variability, J. Climate, 23, 851-867, doi:10.1175/2009jcli3099.1, 2010.

Knapp, K. R.: Inter-satellite bias of the high resolution infrared radiation sounder water vapor channel determined using ISCCP B1 data, J. Appl. Remote Sens., 6, 063523, 
doi:10.1117/1.Jrs.6.063523, 2012.

Lanzante, J. R. and Gahrs, G. E.: The "Clear-Sky Bias" of TOVS Upper-Tropospheric Humidity, J. Climate, 13, 40344041, doi:10.1175/1520-0442(2000)013<4034:tcsbot>2.0.co;2, 2000.

Leathers, D. J., Yarnal, B., and Palecki, M. A.: The Pacific/North American Teleconnection Pattern and United States Climate. Part I: Regional Temperature and Precipitation Associations, J. Climate, 4, 517-528, doi:10.1175/15200442(1991)004<0517:tpatpa>2.0.co;2, 1991.

L'Heureux, M. L., Kumar, A., Bell, G. D., Halpert, M. S., and Higgins, R. W.: Role of the Pacific-North American (PNA) pattern in the 2007 Arctic sea ice decline, Geophys. Res. Lett., 35, L20701, doi:10.1029/2008g1035205, 2008.

Li, J., Yu, R., and Zhou, T.: Teleconnection between NAO and Climate Downstream of the Tibetan Plateau, J. Climate, 21, 46804690, doi:10.1175/2008jcli2053.1, 2008.

Lim, Y. K. and Schubert, S. D.: The impact of ENSO and the Arctic Oscillation on winter temperature extremes in the southeast United States, Geophys. Res. Lett., 38, L15706, doi:10.1029/2011g1048283, 2011.

Lindfors, A. V., Mackenzie, I. A., Tett, S. F. B., and Shi, L.: Climatological Diurnal Cycles in Clear-Sky Brightness Temperatures from the High-Resolution Infrared Radiation Sounder (HIRS), J. Atmos. Ocean. Tech., 28, 1199-1205, doi:10.1175/jtech-d-1100093.1, 2011.

Machado, L. A. T., Rossow, W. B., Guedes, R. L., and Walker, A. W.: Life cycle variations of mesoscale convective systems over the Americas, Mon. Weather Rev., 126, 1630-1654, 1998.

MacKenzie, I. A., Tett, S. F. B., and Lindfors, A. V.: Climate Model-Simulated Diurnal Cycles in HIRS Clear-Sky Brightness Temperatures, J. Climate, 25, 5845-5863, doi:10.1175/jcli-d-1100552.1, 2012.

Mantua, N. J. and Hare, S. R.: The Pacific decadal oscillation, J. Oceanogr., 58, 35-44, 2002.

Mantua, N. J., Hare, S. R., Zhang, Y., Wallace, J. M., and Francis, R. C.: A Pacific interdecadal climate oscillation with impacts on salmon production, B. Am. Meteorol. Soc., 78, 1069-1079, 1997.

Mapes, B. E. and Houze, R. A.: Cloud Clusters and Superclusters over the Oceanic Warm Pool, Mon. Weather Rev., 121, 13981415, 1993.

McCarthy, M. P. and Toumi, R.: Observed interannual variability of tropical troposphere relative humidity, J. Climate, 17, 31813191, 2004.

Minobe, S.: Resonance in bidecadal and pentadecadal climate oscillations over the North Pacific: Role in climatic regime shifts, Geophys. Res. Lett., 26, 855-858, doi:10.1029/1999g1900119, 1999.

Mo, K. C.: Relationships between low-frequency variability in the Southern Hemisphere and sea surface temperature anomalies, J. Climate, 13, 3599-3610, doi:10.1175/15200442(2000)013<3599:Rblfvi>2.0.Co;2, 2000.

Namias, J.: The index cycle and its role in the general circulation, J. Meteor., 7, 130-139, doi:10.1175/15200469(1950)007<0130:TICAIR>2.0.CO;2, 1950.

Newman, M., Compo, G. P., and Alexander, M. A.: ENSO-Forced Variability of the Pacific Decadal Oscillation, J. Climate, 16, 3853-3857, doi:10.1175/1520- 0442(2003)016<3853:evotpd>2.0.co;2, 2003.

Park, T. W., Ho, C. H., and Yang, S.: Relationship between the Arctic Oscillation and Cold Surges over East Asia, J. Climate, 24, 68-83, doi:10.1175/2010jcli3529.1, 2011.

Patara, L., Visbeck, M., Masina, S., Krahmann, G., and Vichi, M.: Marine biogeochemical responses to the North Atlantic Oscillation in a coupled climate model, J. Geophys. Res., 116, C07023, doi:10.1029/2010jc006785, 2011.

Peings, Y., Douville, H., and Terray, P.: Extended winter Pacific North America oscillation as a precursor of the Indian summer monsoon rainfall, Geophys. Res. Lett., 36, L11710, doi:10.1029/2009g1038453, 2009.

Picon, L., Roca, R., Serrar, S., Monge, J. L., and Desbois, M.: A new METEOSAT "water vapor" archive for climate studies, J. Geophys. Res.-Atmos., 108, 4301, doi:10.1029/2002jd002640, 2003.

Press, W. H., Teukolsky, S. A., Vetterling, W. T., and Flannery, B. P.: Numerical recipes: the art of scientific computing, Cambridge University Press, Cambridge, UK, New York, 1256 pp., 2007.

Previdi, M. and Veron, D. E.: North Atlantic cloud cover response to the North Atlantic oscillation and relationship to surface temperature changes, J. Geophys. Res., 112, D07104, doi:10.1029/2006jd007516, 2007.

Rigor, I. G., Wallace, J. M., and Colony, R. L.: Response of Sea Ice to the Arctic Oscillation, J. Climate, 15, 2648-2663, doi:10.1175/1520-0442(2002)015<2648:rositt>2.0.co;2, 2002.

Roca, R., Picon, L., Desbois, M., LeTreut, H., and Morcrette, J. J.: Direct comparison of Meteosat water vapor channel data and general circulation model results, Geophys. Res. Lett., 24, 147150, doi:10.1029/96g103923, 1997.

Ropelewski, C. F., and Halpert, M. S.: Quantifying Southern Oscillation - Precipitation relationships, J. Climate, 9, 1043-1059, doi:10.1175/1520-0442(1996)009<1043:Qsopr>2.0.Co;2, 1996.

Rossow, W. B. and Pearl, C.: 22-Year survey of tropical convection penetrating into the lower stratosphere, Geophys. Res. Lett., 34, L04803, doi:10.1029/2006g1028635, 2007.

Saunders, R., Matricardi, M., and Brunel, P.: An improved fast radiative transfer model for assimilation of satellite radiance observations, Q. J. Roy Meteor. Soc., 125, 1407-1425, doi:10.1256/Smsqj.55614, 1999.

Schreck, C. J., Shi, L., Kossin, J. P., and Bates, J. J.: Identifying the MJO, Equatorial Waves, and Their Impacts Using 32 Years of HIRS Upper-Tropospheric Water Vapor, J. Climate, 26, 1418 1431, doi:10.1175/jcli-d-12-00034.1, 2012.

Shi, L. and Bates, J. J.: Three decades of intersatellite-calibrated High-Resolution Infrared Radiation Sounder upper tropospheric water vapor, J. Geophys. Res.-Atmos., 116, D04108, doi:10.1029/2010jd014847, 2011.

Shi, L., Bates, J. J., and Cao, C.: Scene Radiance-Dependent Intersatellite Biases of HIRS Longwave Channels, J. Atmos. Ocean. Tech., 25, 2219-2229, doi:10.1175/2008jtecha1058.1, 2008.

Soden, B. J.: The diurnal cycle of convection, clouds, and water vapor in the tropical upper troposphere, Geophys. Res. Lett., 27, 2173-2176, 2000.

Soden, B. J. and Bretherton, F. P.: Upper-tropospheric relativehumidity from the GOES 6.7 mu-m channel - method and climatology for July 1987, J. Geophys. Res.-Atmos., 98, 1666916688, doi:10.1029/93jd01283, 1993. 
Soden, B. J. and Lanzante, J. R.: An assessment of satellite and radiosonde climatologies of upper-tropospheric water vapor, J. Climate, 9, 1235-1250, 1996.

Soden, B. J., Jackson, D. L., Ramaswamy, V., Schwarzkopf, M. D., and Huang, X. L.: The radiative signature of upper tropospheric moistening, Science, 310, 841-844, doi:10.1126/science.1115602, 2005.

Sohn, B. J. and Park, S.-C.: Strengthened tropical circulations in past three decades inferred from water vapor transport, J. Geophys. Res., 115, D15112, doi:10.1029/2009jd013713, 2010.

Thompson, D. W. J. and Wallace, J. M.: Annular modes in the extratropical circulation. Part I: Month-to-month variability, J. Climate, 13, 1000-1016, doi:10.1175/15200442(2000)013<1000:Amitec>2.0.Co;2, 2000.

Trenberth, K. E.: The definition of El Nino, B. Am. Meteorol. Soc., 78, 2771-2777, 1997.

Vandeberg, L., Pyomjamsri, A., and Schmetz, J.: Monthly Mean Upper Tropospheric Humidities in Cloud-Free Areas from Meteosat Observations, Int. J. Climatol., 11, 819-826, 1991.

van den Dool, H. M., Saha, S., and Johansson, Å.: Empirical Orthogonal Teleconnections, J. Climate, 13, 1421-1435, doi:10.1175/1520-0442(2000)013<1421:eot>2.0.co;2, 2000.

Vicente-Serrano, S. M. and López-Moreno, J. I.: Nonstationary influence of the North Atlantic Oscillation on European precipitation, J. Geophys. Res., 113, D20120, doi:10.1029/2008jd010382, 2008.
Wallace, J. M. and Gutzler, D. S.: Teleconnections in the Geopotential Height Field during the Northern Hemisphere Winter, Mon. Weather Rev., 109, 784-812, doi:10.1175/15200493(1981)109<0784:titghf>2.0.co;2, 1981.

Wu, X. Q., Bates, J. J., and Khalsa, S. J. S.: A Climatology of the Water-Vapor Band Brightness Temperatures from Noaa Operational Satellites, J. Climate, 6, 1282-1300, 1993.

Wylie, D., Jackson, D. L., Menzel, W. P., and Bates, J. J.: Trends in global cloud cover in two decades of HIRS observations, J. Climate, 18, 3021-3031, 2005.

Wylie, D., Eloranta, E., Spinhirne, J. D., and Palm, S. P.: Comparison of cloud cover statistics from the GLAS lidar with HIRS, J. Climate, 20, 4968-4981, doi:10.1175/Jcli4269.1, 2007.

Wylie, D. P., Menzel, W. P., Woolf, H. M., and Strabala, K. I.: 4 Years of Global Cirrus Cloud Statistics Using Hirs, J. Climate, 7, 1972-1986, 1994.

Yu, L. J., Zhang, Z. H., Zhou, M. Y., Zhong, S., Lenschow, D., Hsu, H. M., Wu, H. D., and Sun, B.: Influence of the Antarctic Oscillation, the Pacific-South American modes and the El Nino-Southern Oscillation on the Antarctic surface temperature and pressure variations, Antarct Sci., 24, 59-76, doi:10.1017/S095410201100054x, 2012.

Zuidema, P.: Convective clouds over the Bay of Bengal, Mon. Weather Rev., 131, 780-798, 2003. 